\title{
From theory to practice of ecotourism: major obstacles that stand in the way and best practices that lead to success
}

https://doi.org/10.1515/ejthr-2017-0004

received 10 May, 2016; accepted 28 December, 2016

\begin{abstract}
Ecotourism has been described as the ideal kind of tourism, as it aims to conserve the natural, cultural and other tourist resources for continuous use for future generations whilst still bringing benefits to the present societies. Theoretically, it sounds so promising and attractive, but when it comes to its actual implementation, significant constraints bar the way to success. Various countries that attempted to foster sustainable development in their communities, either partially achieved their goals or their implementation totally lapsed. These fruitless efforts clearly reflect the huge gap that still exists between the theory and practice of ecotourism. The purpose of this paper is to fill this gap that seems to have been growing in recent years by explaining what has been done wrong and what specific policies and procedures could help bring a positive change. This paper aims to move from theory to practice and concentrate on how the implementation of ecotourism can be achieved properly and lead to success. The key factors responsible for failure are addressed, so they can be avoided and mistakes of the past will not be repeated. It also serves as a guide to more effective strategies of promoting ecotourism successfully around the world.
\end{abstract}

Keywords: Ecotourism; Sustainable development; Protected areas; Authenticity; Carrying capacity

\footnotetext{
*Corresponding author: Christina K. Dimitriou, State University of New York (SUNY) at Plattsburgh, Hotel, Restaurant and Tourism Management Programme, 101 Broad Street - Sibley 403 H, Plattsburgh, NY 12901 USA, Tel: 001-518-564-3182 Fax: 001-518-564-3263 E-mail: christina.dimitriou@plattsburgh.edu
}

\section{Introduction}

Tourism and the environment are closely linked together. The environment is a key resource, and consequently its conservation and management are vital both to the future of the tourism industry and to the society as a whole' (Green, Hunter \& Moore, 1990, p. 11). In addition, it is necessary to always remember that the physical (natural and man-made) environment provides many of the attractions for tourists and tourism itself can create positive as well as negative impacts. A lesson learned through the years, and sadly the hard way, is that even though tourism may be able to generate great opportunities and wealth for developed as well as developing countries across the world, it also has a price: the potential to damage and destroy the very resources on which it depends, if not planned and considered carefully. The uncontrolled expansion of mass tourism that mostly characterised the 1960 s clearly proved how true this is and obliged researchers, tourism experts and others to re-evaluate the international tourism development and gain great environmental concern over the tourism's growth. Nowadays, the promotion of a more sustainable and eco-friendly approach and the need to develop responsible tourism policies have become the top priority of the tourist industry and the local governments. As Wheeller (1996) made clear, 'the tourism product is the environment, tourism depends on the environment for its continuing success; therefore it is in tourism's interest to preserve and enhance the environment' (p. 15).

One of the main names that are used to describe this more responsible, 'greener' form of tourism was ecotourism. It must be noted, though, that it is a mistake to interpret ecotourism only in terms of preserving sensitive and vulnerable ecosystems or natural habitats that are threatened of serious damage. Ecotourism also embraces the protection of human cultures that can be totally destroyed or become inauthentic and are sensitive as well. As Sir Cripsin Tickell (Cater \& Lowman, 1994) ascertained, 'The 
sensitivity of human cultures is often forgotten. In some places the vestigial remains of old cultures have been put at risk by our enthusiasm for them. At Lascaux in France the Magdalenian cave paintings of 13,000 to 14,000 years ago have become gravely contaminated as a result of visitors, in particular their breadth and moisture. In Egypt ancient sites are being destroyed by the constant pounding of visitors' feet' (p. ix). The economy of New Zealand is based on tourism which is a key source of employment. However, the erosion and consumption of fossil fuels, as well as the pollution and waste created by tourism, have severely threatened the country's natural resources and forced people to consider ecotourism as the antidote (Freeman, 2014). Zambia also relies heavily on tourism as one of its main sources of economic growth (Thapa, 2013). The increased numbers of international tourists who are attracted to the country's parks, protected areas and other wildlife-based destinations have created the need for visitor management and the implementation of ecotourism. Carreiro (2014) described the damage that uncontrolled tourism caused to India and especially to Goa and expressed the need for ecotourism that respects local cultures, includes and involves the local people in the tourism process and offers long-term sustainability and conservation.

Taking into consideration the current situation and the challenges that many tourist destinations face today, it is truly remarkable to note that this critical issue of the damage and deterioration of the natural resources of this planet - which is still so intensely recognised - has been stated ages ago. The Greek philosopher, Plato, 'in Critias written some 2.400 years ago, described massive deforestation and soil erosion stemming largely from agricultural pursuits on the Mediterranean island of Attica. He concluded: ...just as happens in small islands, what now remains compared with what then existed is like the skeleton of a sick man, all the fat and soft earth having been wasted away, and only the bare framework of the land being left' (as cited in Harris \& Leiper, 1995, p. xviii).

Ecotourism could be described as the ideal kind of tourism that harmonises its activities with what is best for the environment whilst simultaneously building a solid basis for long-term growth. Its principles sound very promising with great potential. Theoretically, it consists of the perfect tourism development, small scale, steady and controlled, but there are doubts to what extent it can become a realistic tourism development and can be implemented successfully. As Gilbert, Penda and Friel (1994) contended, "the question is therefore one of whether realism should prevail in terms of acceptance that there will always be conflicts of cost and benefit related to all forms of tourism, or whether idealism should dominate whereby coexistence of tourists' needs and small scale development is one means of dealing with the conflicts' (p. 33). Things get more complicated when the majority of research revolves around developed countries and developing countries, particularly Africa and Central and South America, are ignored or under-represented ( $\mathrm{Lu} \& \mathrm{Nepal}$ 2009). This is so unfair, as the emphasis should be placed on both the destinations that have been damaged as well as those that are still virgin, unspoiled and untouched.

The purpose of this paper is to examine where the gap lies between ecotourism's theory and practice and how it could be bridged. The goal is to show how the theoretical approach and conceptual framework of ecotourism can be linked to its successful implementation and explain those factors that may lead to failure. In order to achieve that, the paper is divided in three sections: The first section covers the theoretical part where the definitions and the concept of ecotourism are addressed. The second section focuses on the ineffective practice and implementation of ecotourism where an attempt is made to identify and explain the major obstacles that block the path to success. The third section presents best practices that can positively contribute to sustainability in tourism and create a better future for this industry.

\section{Ecotourism: the theory}

\subsection{Defining ecotourism}

Ecotourism is one of the most debated subjects over the recent years. Plenty of comments, different ideas, opinions and approaches have been written and expressed about ecotourism, which clearly show that tourism experts and researchers still haven't managed to reach a common ground and there is much confusion over its terminology and concepts (Dimitriou, 2000). Tourism literature offers a variety of terms to describe this type of tourism: 'small scale', 'appropriate', 'alternative', 'controlled', 'ecotourism', 'green', 'nature', 'soft', 'responsible', 'environmentally sensitive', 'sustainable' and so on. According to Godfrey (1998), most of this confusion stems from 'the pre-occupation of some to avoid the mass tourism label, which functions in this context as a repulsive point of reference' (pp. 213-214) and use instead a selection of words and synonyms that would imply how different, milder and better ecotourism is compared to mass tourism. 
When it comes to defining ecotourism, a number of different definitions have been used. Lindberg, Enriquez and Sproule (1996) not only recognised the lack of a widely accepted definition of ecotourism, but also in their effort to explain the meaning of ecotourism added that 'many experts involved in the ecotourism field assess that tourism should satisfy conservation and development objectives in order to be considered ecotourism' (p. 543). Orams (1995) defined ecotourism as 'tourism which is based on the natural environment and seeks to minimize its negative impact on that environment' (p. 5). Björk (2000) in his effort to clarify any misconceptions and misuses of this kind of tourism pointed out that 'ecotourism is not farm tourism, nature tourism or adventure tourism, but a unique tourism form that has become very popular due to the greening of markets, increasing knowledge of the fragility of the environment, better informed managers, and the recognition that there is a close relationship between good ecology and good economy' ( $p$. 189). Krippendorf (1987) used the term alternative tourism and provided a very detailed description regarding what it entails. More specifically, he supported that 'the term is most often used for traveling in or to, the Third World, but sometimes it is applied to other countries. The guiding principle of alternative tourists is to put as much distance as possible between themselves and mass tourism. They try to avoid the beaten track, they want to do things which will bring them a sense of adventure and help them to forget civilization for a while. Alternative tourists try to establish more contact with the local population, they try to do without the tourist infrastructure and they use the same accommodation and transport facilities as the natives. They also want to get more information before and during their holiday. They travel alone or in small groups' (Krippendorf, 1987, p. 37). Smith and Eadington (1992) noted that 'alternative tourism is broadly defined as forms of tourism that are consistent with natural, social and community values and which allow both hosts and guests to enjoy and worthwhile interaction and shared experiences' (p. 3). In recent years, further attempts to define ecotourism 'have centered on conservation, education, ethics, sustainability, impacts and local benefits as the main variables' (Chiutsi, Mukoroverwa, Karigambe \& Mudzengi, 2011, p. 14).

In this paper, the term 'ecotourism' is interpreted as the type of tourism that includes the following central themes: First, ecotourism develops in a way that will not damage the environment, physical and general; avoids the negative effects that large-scale tourism has caused; and carefully manages the resources so that they are available for future generations. Second, it consists of 'smaller developments, or attractions for tourists which are set in and organized by villages and communities' (Smith \& Eadington, 1992, p. 52). Third, local people are involved and most of the benefits will flow to them without flowing away to other places or abroad in the form of leakages. Fourth, ecotourism meets 'the needs rather than demands' (Romeril, 1994, p. 28). The final theme is to promote cultural sustainability. Ecotourism development respects and conserves the culture of the host community without causing any damage or change. The element of authenticity is strongly emphasised.

However, one thing that needs to be highlighted, at this stage, is that some people just do not seem to worry so much about finding the exact definition of ecotourism but draw attention instead to other more crucial aspects of this 'green' form of tourism. For example, Gilbert, Pend and Friel (1994) contended that no matter how it is called, the main issue is that it consists of a 'more benign form of tourism or even one with positive benefits' (p. 3). Furthermore, Romeril (1994) argued: 'what does it matter if the definition is not strictly appropriate if the activity is environmentally sensitive and sound? Surely it is the philosophy and not the semantics, that is important' (p. 25).

\subsection{The concept of ecotourism}

Even though 'the concept of ecotourism came into vogue in the late 1980's' (Wild, 1994, p. 12), it is surprising that it is still not clear what exactly this kind of tourism is all about. As Björk (2000) stated, 'what kind of areas ecotourism incorporates is not always obvious in the literature' (p. 189). Furthermore, Bottrill and Pearce's (1995) remark that 'increasing usage of the term ecotourism has done little to clarify the concept' (p. 45) expresses accurately the current situation, even after all these years. Orams (1995) supported that the increased number of definitions of ecotourism signals the fact that it means different things to different people. Järviluoma (1992) approached ecotourism from the perspective that it is 'small scale developed by local people and based on local nature and culture' (p. 118) and stressed the importance of respecting the 'environmental and social carrying capacity' of a tourist destination. Others (Butler 1992; Weaver, 1995) viewed ecotourism as anything other than mass tourism or even the alternative to mass tourism. There were also those (Jefferson, 1995) who examined ecotourism through a political perspective and contended that its development 'must be politically acceptable' and 'socially responsible and environmentally sound' (p. 104). 
In a more general sense, one could argue that ecotourism has been promoted as an idea and philosophy that involves responsible travel to natural areas, conserves the environment and implies thought and concern. Nevertheless, this review of the variety of meanings and concepts given to ecotourism implies that the debate over what this type of tourism really is, continues. However, this paper supports that ecotourism's concept is based on the widespread and growing interest in the natural environment and the importance of conserving and protecting it in any possible way from detrimental impacts and deterioration.

\subsection{Principles and goals of ecotourism}

Ecotourism has been presented as a more caring, softer and greener form of tourism. Its primary goal is to conserve an area's cultural heritage, protect and enhance the environment as well as focus on the socio-economic sustainability of a tourist destination. Emphasis is given on maintaining the unique sense of historic, cultural and community identity of each place. Archer and Cooper's (1994) described ecotourism as the kind of tourism that 'demands a long-term view of economic activity, questions the imperative of continued economic growth, and endures that consumption of tourism does not exceed the ability of the host destination to provide for future tourists' (p. 87). Ecotourism aims to mitigate the negative impacts associated with tourism development through thoughtful policy-making and planning, but above all, it requires change in tourists' attitude and growing awareness on how to achieve ecotourism development. In addition, ecotourism aspires to 'the conservation of the productive basis of the physical environment by preserving the integrity of the biota and ecological processes, maintaining diversity, and producing tourism commodities without degrading other values' (Hall \& Wouter 1994, p. 369). Most significantly, though, one of the main objectives of ecotourism development is 'to reduce the poverty of the world's poor by providing lasting and secure livelihoods, which entails minimizing resource depletion, cultural disruption and social instability...it places emphasis on the host population's economy society and culture' (Curry \& Morvaridi, 1992). In that respect, the local community plays a key role and acts as the main ingredient that can lead to success.

Choi and Sirakaya (2006) noted that 'sustainable tourism policies should provide workable definitions, principles, implementation strategies, action plans and a monitoring system of sustainable development for community tourism development (CTD) with consideration of the entire spectrum of economic, social, cultural, natural, technological and political environments' (p. 1277).

'The other key consideration to community involvement in ecotourism is the claim that local residents provide authenticity and value to the ecotourism experience with their deep and privileged knowledge about their culture and overall tourism resource base in the destination area' (Chiutsi et al., p. 17).

According to James R. Butler (as cited in Scace, 1993, p. 65), the following eight descriptive characteristics are consistent with an ecotourism experience:

1. It must be consistent with a positive environmental ethic, fostering preferred behaviour.

2. It does not denigrate the resource. There is no erosion of resource integrity.

3. It concentrates on intrinsic rather than extrinsic values.

4. It is biocentric rather than homocentric in philosophy, in that an ecotourist accepts nature largely in its terms, rather than significantly transforming the environment for personal convenience.

5. Ecotourism must benefit the resource. The environment must experience a net benefit from the activity, although there are often spin-offs of social, economic, political or scientific benefits.

6. It is a first-hand experience with the natural environment.

7. There is an ecotourism, an expectation of gratification measured in appreciation and education, not in thrill-seeking or physical achievement. These latter elements are consistent with adventure tourism, the other division of natural environment (wildland) tourism.

8. There are high cognitive (informational) and effective (emotional) dimensions to the experience, requiring a high level of preparation from both leaders and participants.

When it comes to the principles that should underlie the concept of ecotourism, Wight (as cited in Gunn, 1994, p. 98) presented the following:

1. It should not degrade the resource and should be developed in an environmentally sensitive manner.

2. It should provide first-hand, participatory and enlightening experience.

3. It should involve education amongst all parties - local communities, government, non-government organisations, industry and tourists (before, during and after the trip). 
4. It should incorporate all party recognition of core values related to the intrinsic values of the resource.

5. It should involve acceptance of the resource on its own terms and in recognition of its limits, which involves supply-oriented management.

6. It should promote understanding and involve partnerships between many players, which could include government, non-governmental organisations, industry scientists and locals (both before development and during operation).

7. It should promote moral and ethical responsibilities and behaviour by all players.

8. It should provide long-term benefits: to the resource, the local community and industry (benefits may be conservation, scientific, social, cultural or economic). variations (eco-vacation, eco-tour, eco-adventure, ecocruise, etc.) were introduced in tourism offers operators only as simple words, tricks to attract a wide range of tourists, or to enter and to benefit from the special natural and cultural areas' (Cheia, 2013, p. 59).

'Tourism development typically benefits the middles classes, as opposed to the poor, with the latter most affected by the negative impacts of tourism' (Cohen \& Cohen, 2012, p. 2187). However, Wheeller (1992b) supported that for educated tourists, 'it is immediately appealing for it conveniently appeases any guilt while simultaneously providing the increased holiday options and experience desired' (p. 141).

\subsection{Major obstacles that block the path to success}

\section{From theory to practice: major obstacles and ineffective practices in the implementation of ecotourism}

\subsection{Problems with ecotourism}

Ecotourism is amongst those few topics offered in the tourism literature that have been debated, discussed and researched on a theoretical level, but hasn't managed to advance much on the application and implementation level (Cohen \& Cohen 2012; Walker \& Moscardo, 2014). Despite the amount of articles and theories that have been written on ecotourism, in terms of figuring out the successful implementation of ecotourism and mastering the art of practicing what has been preached are both still at an early stage. This is not at all surprising when taking into consideration the confusion that exists in ecotourism's definition, concepts and principles and coupled with the fact that it has been misused and misinterpreted so poorly for several decades (Björk, 2000, Wall, 1997) on a practical level.

Wheeller (1991; 1992a; 1992b; 1993a; 1993b; 1996) has been one of the foremost questioners of ecotourism who has seriously considered and carefully examined its concept and development at a deep level, bringing into surface elements that encourage further research. He was one of the first to address the issue that regarding ecotourism, things may not always be as nice and good as they seem, as hidden dangers and traps that cannot be easily seen may exist. 'Often, however, this term and its
Theoretically, ecotourism is the ideal kind of tourism that sounds promising and attractive. As many people (Pigram 1990; Wheeller 1991; Wheeller1992b; Buckley 2009) strongly argued, there is a huge gap between the theory of ecotourism and its actual implementation. There are great difficulties in trying to translate it into practice as significant constraints bar the way to success.

The first major difficulty depends on the fact that tourism development takes place in a diverse range of environments in many different social and political contexts (Archer \& Cooper, 1994; Shaw \& Williams, 1992). Each country or region is unique with particular characteristics, so development approaches must be adapted in accordance to each specific destination. It should be highlighted that 'some habitats we know are significantly more fragile than others and require detailed knowledge to minimize impacts' (Gauthier, 1993, p. 106). Furthermore, De Kadt's (1992) statement that 'not all policies have identical implications for implementation' (p. 66) couldn't be more true, contemporary and accurate when it comes to the issue of explaining why there are barriers in applying ecotourism successfully in different areas and regions. In other words, it is critical to understand that what works in one place does not mean that it will also work in another, so extra attention should be given on each destination's particularities. Lu and Nepal (2009) stressed how crucial this principle is, especially in the case of the developing countries 'where culture, social norms and political contexts are very different than they are in the developed world' (p. 14).

Another important obstacle stems from the concept of visitor management that always comes up in any conversations evolving around ecotourism and sustainable 
policies. Tourism experts and professionals know how challenging and hard it can be to control the number of tourists who will visit a specific tourist destination. The main problem with ecotourists is that they are attracted to 'out-of-the-way areas which often cannot sustain intensive human activities' (Ioannides, 1995, p. 585). Therefore, fragile destinations with very limited capacity suffer from heavy visitor pressure and eventually get destroyed.

An additional key obstacle that is closely linked to the previous one is how to identify and agree upon capacity levels that will determine the number of tourists that a tourist destination can withstand. This is extremely difficult and requires careful attention on behalf of tourism planners. Butler (1993) in his effort to approach this obstacle noted: 'it is possible to set limits to change and rates of change, but the problem with setting limits is that people have different views on what limits are available' (p. 140).

An even more challenging obstacle is that whilst ecotourism may increase local involvement in order to generate additional income for the communities, there are still many powerful transnational companies that control ecotourist flows. Therefore, the destination manages to get only a small proportion of the income generated by tourism. Indeed, Murphy (1985) was ahead of his time when he argued that there are scarce good models of community participation and planning in tourism.

Pigram (1992) identified a further obstacle that stands in the way to success by warning that 'implementation is likely to lapse or be only partial without a positive response from the community affected in support of change' ( $\mathrm{p}$. 85). Sometimes, local communities themselves oppose to sustainable development and the implementation of ecotourism. Butler (1992) explained that the preferences of local communities in some cases do not match the goals of alternative tourism proponents. Other times, local communities do not even have the chance to participate in the decision processes because of the fact that their visions and opinions are ignored. The Akamas case in Cyprus is a characteristic example, as the tourism planners were reluctant to listen to the hosts' point of view. They thought that it would be better not to involve them in their plan 'fearing it would stir up trouble among interest groups' (Ioannides, 1995, p. 590).

The many different interest groups of stakeholders involved in ecotourism management consist of another crucial barrier. 'These include government, individual enterprises, "green" and non-"green" consumers and good practice groups and community-based groups. Without an understanding of the views of such stakeholders, it will be difficult to consult successfully and to develop effective partnerships with all those involved' (Bramwell, Henry,
Jackson \& Van der Straaten, 1996, p. 59). The major challenge in this case is that it is almost impossible for all these parties to cooperate and achieve an integrated approach in order to tackle regional problems and foster ecotourism because of their conflicting interests. In fact, this can generate more implications such as local residents' protestation, for example, some villagers in the Akamas region 'threatened that if the government proceeds with its environmental conservation/sustainable tourism they may resort to extreme measures such as setting fire to the national forest or destroying the turtle nesting grounds' (Ioannides, 1995, p. 590). This form of tourism should support economically viable and long-lasting operations with economic benefits appropriately distributed to all stakeholders and promote stable employment and the possibility of benefits and social services for hosting communities, contributing to poverty reduction. (Musarò, p. 102) However, as Timothy (1998) supported, 'there is a significant lack of research on tourism planning in developing countries, even though it is clear that planning and the political environments in which planning occurs are very different from those in developed, Western societies' (p.66). What is even more interesting is that Timothy's (1998) study found that developing countries suffer from a lack of cooperative tourism planning because of socio-political factors.

Additionally, in order to put in practice ecotourism policies, it is necessary to invest money in infrastructure. However, Lane (1994) argued that funding can be slow and a very difficult task. Indeed, identifying sources of funding and getting them to support any kind of tourism project, not just environmentally-friendly and sustainable ones, has been and will always remain a challenge for every nation, destination or region, especially during tough economic times. Apart from the financial aspect, though, the issue of authenticity also comes into play and raises critical concerns. How can a destination preserve and protect its local culture, costumes and other folklore aspects. To what extent the temptation to transform local traditions to foreign-friendly acceptable practices can be avoided? What about authenticity? According to Cohen and Cohen (2012), 'the rapidly expanding non-Western, particularly Asian, tourism was from the outset driven by other motives than a quest for authenticity' (p. 2179). Indeed, this is a trap that many destinations can easily fall into. Violating this core principle of ecotourism can backfire and the consequences can be much more detrimental when it extends and covers a whole continent rather than just a small local area or region. Xu, Cui, Sofield and Li's (2014) study on ecotourism in protected areas in China discussed how the strategy of imposing Western standard 
ecotourism practices is quite risky, as it can bring the opposite results across the country. This paper agrees fully with Musarô's (2015) statement that ecotourism 'should respect the socio-cultural authenticity of host communities, preserving their typical building structures, their cultural heritage and traditional values, and cooperating for better intercultural understanding' (p. 102) and contends that countries that ignore this key principle will continue to fail in their efforts to become sustainable.

During the 1990s when tourism experts were trying to move away from mass tourism and figure out how to turn to a more environmentally-friendly form of tourism, Hunter (1995) argued that ecotourism could become 'a vital mechanism for environmental education, the protection of ecologically valuable habitats and job creation and economic development in many areas around the world' (p. 83). However, so far this has proven to be one of the major challenges that stand in the way to success. To successfully foster ecotourism, destinations need specially trained, highly skilled staff in order to achieve both sustainable development and management. That's all good in theory but when it comes to the actual implementation, key concerns that still pose a problem and have yet to be answered arise. These include the following: Can ecotourism achieve to create enlightened and critical consumers? Who will train the tourists? Who will train the trainers, the rangers and the tour guides and how they will be trained? Moreover, Wheeller (1991) raised further questions such as who will pay and on what time span the education process will start showing its positive effects. Surprisingly enough, so many years later, as Buckley (2009) noted, there still is a lack of 'any controlled longitudinal study to test whether clients of commercial ecotours change their post-trip lifestyles or political activities so as to reduce environmental impacts or enhance conservation' (p. 656). Careful exploration of this topic in future research would significantly help the tourist industry gain a better understanding of where it should place its focus and emphasis regarding this issue.

Walker and Moscardo (2014) noted that further research is needed on how to train tour guides to be able to apply the learning mechanisms of 'mindfulness, reflection and personal insight and develop related performance indicators' (p. 1191).

There are also issues regarding the effectiveness of training. Can training bring the desired results? Does training have the power to change tourist's behaviours or will it simply prove to be a waste of time? Wheeller (1991) contended that 'the notion of educating the tourist/traveller in destination awareness is surely idealistic' (p.92). Bramwell (1990) stated that 'it is foolishly credulous to expect education on its own to work miracles and manage to convert everybody towards a more environmentally-friendly attitude. Even if the majority of tourists become educated, there is no guarantee that they will ever apply what they will have learnt. Education might increase environmental awareness, but it still cannot solve the problem' (p. 360). Cater (1994) argued that a great deal of eco-friendly tourists who visit a tourist destination for a few days and may never return to it adopt a careless attitude towards the use of resources without considering the long-term repercussions of their activities. It is hardly convincing that ecotourists will ever care for anything more than the improvement of their image, their own pleasure and satisfaction. Wheeller (1993a, 1993b) noted that ecotourism should be read as egotourism. He based his philosophy on the idea that people do not really care so much neither for the preservation of the endangered environments nor for what the future generations will be able to see. He claimed that what they are really after is to massage their egos and present the better possible image of themselves. There is always the risk that their immediate personal gains will always dominate their choices and actions and it could be very unlikely that ecotourism will manage to change that. Apart from raising the tourists' awareness, though, it is equally important to inform and educate owners, managers, supervisors, employees and residents as well which makes it even more complicated and difficult to achieve.

Despite other barriers, there are also suspicions that the tourist industry's shift towards a more environmentally friendly form of ecotourism may only be a marketing ploy. According to Prosser (1994), 'tour operators are reaching to the changing demands, attitudes and expectations among customers by marketing their green credentials' (p. 35). Scace (1993) mentioned that suppliers apply the eco label as merely a marketing tool to create tourist packages such as trips to fragile areas that do not include any ecotourism principles, standards or criteria. Similarly, Wight (1993) noted that 'green' sells. In fact, she argued that terms prefixed with 'eco' such as ecosafari, ecotravel and so on give significant rise to interest and sales even if sometimes the product sold is totally unrelated to ecotourism. Taking into consideration the countless travel agencies and other tourist organisations that went down that path throughout all these years, it is no wonder that not much progress has occurred. In addition, a major question arises: How can change take place and how can obstacles be overcome when the actual tourist representatives themselves do not genuinely care for the promotion of ecotourism and are far more concerned about satisfying their own needs and interests? 
Finally, on theoretical level, 'information and education from local or central government and tourism agencies can make the local public, tourists and companies more aware of the environmental problems associated with tourism, and their role in generating and alleviating problems' (Hunter 1995, p. 87). However, in practice, this is not so easy to achieve. How can all these people be educated and persuaded to start acting in a 'greener' way and realise the damage they themselves create? As far as tourists are concerned, Butler (1993) stated: 'I don't think you can convert everybody to sustainable tourism - some people for good reasons of their own like to have a sun, sand and surf holiday' (p. 40). This paper argues that even if tourism planners find the right mechanisms or techniques and put them into action in order to educate people, there will always be some 'narrow-minded' ones or others who will object and refuse to adapt themselves to the new green environment.

All these obstacles and barriers should be taken into careful consideration and not be ignored. In trying to implement ecotourism and focus on approaches to sustainable tourism management, some ways must be found so as to discover solutions for minimising the difficulties. Efficient tourism planning frameworks and the tools to implement environmental management are not only required but also needed now more than ever.

\section{Best practices in the implementa- tion of ecotourism}

Given the complexity of the many parties involved in ecotourism, it becomes apparent that one member individually cannot bring change. Tourism will never become environmentally sustainable if there is a lack of acceptance and cooperation between the various constituencies. Above all, this paper supports that the tourist industry itself should work closely with environmental organisations towards 'green' and eco-friendly policy formulations when it will finally realise that it is directly affected and the preservation of environmental quality is an economic investment with significant profits involved.

There is also a dire need for strong government intervention. It would be foolish to expect tourists to contribute in the promotion of ecotourism by taking initiatives of their own. Therefore, regulation is the primary concern that governments should be after. Strict measures should be taken on all the fragile areas and codes of practice and ethics should not only be set but also ensure that they are actually followed. In addition, governments must be willing and prepared to invest any amount of money needed to cover potential expenses as well as creating organisations or associations that will help promote the desired goals. As far as the latter is concerned, the Ecotourism Association of Australia (EAA), which was established in 1992, is a great example, as it aims to 'promote ecotourism, develop ethics and standards for ecotourism, promote understanding, appreciation and conservation of the natural and cultural environments visited, and facilitate interaction between tourists, host communities, the tourism industry, government and conservation groups' (Weiler, 1995, p. 64).

It is important to understand that simply introducing guidelines for ecotourists is still not enough. There must be constant and careful control in order to ensure that the rules are followed. Discipline should also be enforced and actions should be taken against those who refuse to abide by them. Additionally, local authorities must support and positively respond to such national governmental initiatives. In turn, national governments ought to support and promote policies proposed by international governmental and non-governmental organisations. Obviously, this presumes well-established national and international networking channels to support such an organised campaign in tourist development.

Another proposal that this paper offers refers to tourism planners, experts and decision-makers, as they play a major role in the sustainable management practice. The lesson learned from various unsuccessful attempts to implement ecotourism is based on the fact that frivolous reckless plans lead to undesirable effects. In order to avoid that, there is a strong need for plans to include clear priorities on their sustainable policy practice, which are prepared in a way that strives to increase in the best way possible the tourism experts' knowledge over the destinations the plans are targeted. A thorough and careful examination of the potential repercussions of the actions of these plans should also be addressed.

Developing countries have struggled a lot to gain their own share of ecotourists and promote sustainable tourism development across their regions, especially many of them rely heavily on tourism for economic survival and growth. In this case, the key is to get all the players involved to understand the role they are playing, take ownership of their responsibilities and stay motivated towards becoming 'greener' for it is only then that policies will 'eventually emerge that reflect the needs and interests of all concerned' (Hawkins, 1994, p. 272). The first step is to increase awareness and involve all parties in the tourism process through collective decision-making and through getting 
people to understand how they can benefit overall and in the long term from such an initiative. The most difficult part, though, would be to encourage parties to be more concerned for the destination's and the community's interests instead of focusing on their own personal interest and short-term personal gains. This paper suggests that careful consideration of the needs of each region and how grouped together they can all be addressed to the country as a whole is required, as it would help countries to see the big picture by putting all the pieces together.

Through the years, many countries began to realise the great urgency to move towards a more sustainable form of tourism, safeguard their environment and develop their damaged or fragile areas in every way they could. In the 1990s, several countries took the initiative to implement ecotourism practices and become 'greener'. For example, Los Tuxtlas in Veracruz promoted a strategy that focused on 'the region as a whole consolidating diverse activities involving areas of environment, health, sports, cultural events and even aesthetics' (MacKinnon, 1995, p. 46), supporting that when they are structured and planned carefully, they encourage tourists to extent their length of stay. The purpose was to create a regional image that portrayed tourists as guests and communities as hosts and established a solid basis for social integration and development. The government of Bhutan, which is located in the Eastern Himalayan Mountains of Asia followed a strong policy to control tourism and its undesirable impacts by limiting the tourist arrivals. This policy required that all tourists come on package tours and obtain visas before arrival. This way, the government was able to monitor the travel movement of all tourists (Inskeep, 1994). In Maldives, the local government established carrying capacity standards for each resort island. In addition, the government applied several measures in order to protect the environment, such as controls of the marine ecology, controls on the heights of buildings and controls on turtle products, as far as the socio-cultural and economic considerations were concerned; several policies, rules and regulations were set so as to control tourists' actions. During the 1990s, Maldives were amongst the first countries to set a good example of a destination that tried to retain the local codes and customs (in their case, the Islamic) and chose to hire Maldivians as employees in their resorts rather than foreigners, and their Ministry of Tourism put forward a public education programme to inform all residents about tourism. During the same time, Seychelles, in their efforts to deal with the awful transformation from an unspoiled paradise to a destination suffering from serious cultural and environmental impacts, exercised close control over tourism. Croall (1995) noted that the government of this small republic took the following restrictive measures to promote ecotourism: 'Designating nearly half the island as national park. Putting a ceiling on the number of beds on the three largest islands. Forbidding any hotel to be built higher than a palm tree. Confining motorized water sports to just a few beaches. Encouraging tourists to travel by bicycle or ox-cart to their hotel. Forbidding motorcycles and camping. Banning land sales to foreigners. Keeping three of the islands as bird sanctuaries, to which visits are strictly rationed' (p. 28). Todd and Williams (1996) demonstrated how an Environmental Management Systems model offers a solid management foundation through which sustainability objectives can be attained. Even though their study was focused on American ski areas, their results showed that they could also be successfully applied to other tourism businesses.

A number of further efforts and attempts to promote ecotourism successfully have also occurred in recent years. Georgiev (2010) addressed the issue of the negative impact of uncontrolled tourism in Bulgaria and the need to turn to ecotourism in order to remedy what has been destroyed as well as protect the fragile virgin areas that are still left untouched. In order to achieve that goal, the country put together a political outline that included government rules and regulations, environmental and forestry policies, entrepreneurship initiatives, local growth and development, where stakeholders of ecotourism were strongly represented by local authorities, non-government organisations, investors and so on. During the period 2009-2013, there was also the National Strategy for sustainable tourism in Bulgaria which set 'the development framework in the field of tourism together with the priorities for sustainable development of the sector' (p. 337). Furthermore, all the fragile Bulgarian regions are guided and operated by a specific network of nature protection areas in the territory of the European Union, which is called NATURA 2000. Sandu's (2014) study compared Brussels to Brasov counties to show the importance of implementation of responsible and well-planned ecotourism practices. The former is a mature tourist destination that follows the EU laws and regulations regarding sustainability, whereas the latter is a destination that is now developing and would have a lot to benefit from if it followed the steps of Brussels and use it as an example. Brussels have been so successful in their implementation of ecotourism that it has made a big difference and helped significantly both the area as well as the population. The environmental resources are well preserved, and socio-cultural impacts are also carefully evaluated and protected. More specifically, the implemented projects offered disabled people a much better quality of life, whereas Brasov 
counties showed how significant gender equality at work on a social level, as it brings balance and creates healthy societies. Demonja and Gredičak's (2014) study in Croatia explained the country's efforts to encourage cultural tourism-sustainable development as well as how Croatia could be benefited in every level - regional and national. These benefits include the following: 'Tourist valorization of cultural heritage increases the number of visitors to cultural institutions, creates new revenue sources and alternative sources of funding. Financing sources open opportunities to find new partners for the implementation of marketing activities' (p. 177). Carreiro (2014) suggested three ways to promote ecotourism in India: (a) village home stays, (b) wildlife ecotourism and (c) tribal tourism. Koščak, ColaričJakše and Veljković (2014) discussed the multi-stakeholder approach, which proved to be really effective in the implementation of sustainable practices is Sloavania. They also presented a case study on 'Heritage trails through Dolenjska and Bela krajina in South East Slovenia', which 'was a huge organizational and professional undertaking, supported on all levels by tourism, political and economic stakeholders and having wide social support, therefore positively implemented and in some way still alive today. Despite the fact, that the partnership for development no longer exists, tourism products, which emerged through this project, are still well marketed' (p. 199).

These are only few indicative examples of the many attempts on behalf of tourism governments and organizations throughout the world to safeguard and preserve the natural resources and foster ecotourism. It could be supported that they serve as a ray of hope that shows that the theories and principles of ecotourism can actually be implemented successfully, if planned carefully. These examples could also become a source of inspiration to other destinations to follow their steps and the example they have set. It may be a slow progress, but all these initiatives teach the tourist industry and its professionals helpful lessons on what works on different settings, what practices are most effective and how to proceed. These may still be baby steps, but they do indicate that the industry is moving in the right direction and can actually bring a positive change.

\section{Conclusion}

Tourism is a major industry and its growth as a social phenomenon has been significant. The rapid expansion of tourist activities, though, has caused serious costs and 'illnesses', apart from the benefits and blessings it has brought. The effects of tourism development, especially on the environment, primarily due to the sheer volume of tourists and their heavy concentration in one particular area of a country or region have caused serious to almost irreparable damage. Global climate change, ozone loss, erosion of soils and beaches, deforestation, disappearing species, air, noise, water pollution and toxic waste are only some of the main detrimental impacts that the irresponsible and uncontrolled mass tourism has spread on the destinations it touched.

Ecotourism was built on the hope that it will tackle the problems of mass tourism, minimise the conflicts between tourism and the environment, diminish the impacts on the environment (physical and general) and prevent tourism development from relying only on the short- and intermediate-term economic criteria, as it was happening in the past. Ecotourism's birth was based on ensuring that resources are wisely managed today so that they are available for future generations.

The ideas presented in this paper comprise the basic framework that could move the tourist industry closer to an eco-friendly model. It is hard to deny that the obstacles are still there and will not easily go away. It will take a long time and plenty of hard work and commitment to this goal before ecotourism overcomes its serious difficulties and sets on a path to success not only on a regional or national level, but globally as well. It is crucial to know, though, that ecotourism can actually become a reality and has the ability to be implemented effectively. Successful practices on behalf of some governments proudly prove that. However, it must be recognised that this is not a onetime thing, but a continuous fight which requires rigorous and collective efforts of all the parties involved. Better planning, learning from past mistakes, closer monitoring and evaluation of results are key ingredients to success and strong indicators that this is the right path to follow. If the tourist industry changes its rigid economic goals and attitude, shapes up and does not underestimate the value and significant contribution of the baby steps taken, it will gradually become quite 'greener', more environmentally friendly and ecotourism-sound. Indeed, this is not as important in the short term as much as it is in the long term, as it not only applies what the concept of ecotourism dictates, but also creates a better future for the generations to come. 


\section{References}

[1] Archer, B., \& Cooper C., (1994). The positive and negative impacts of tourism. In W. Theobald (Ed.), Global tourism: The next decade (pp. 73-91). Oxford, U.K.: Butterworth Heinemann Ltd

[2] Björk, P. (2000). Ecotourism from a conceptual perspective, an extended definition of a unique tourism form. International Journal of Tourism Research, 2(3), 189-202

[3] Boo, E. (1995). Ecotourism planning for protected areas. In K. Lindberg, \& D. E. Hawkins (Eds.), Ecotourism: A guide for planners and managers (pp. 15-31). North Bennington: The Ecotourism Society

[4] Bottrill, C., \& Pearce, D. (1995). Ecotourism: Towards a key elements approach to operationalizing the concept. Journal of Sustainable Tourism, 3(1), 45-54

[5] Bramwell, B. (1990). Green tourism in the countryside. Tourism Management, 11(2) 358-360

[6] Bramwell, B., Henry, I., Jackson, G., \& Van der Straaten. J. (1996). A framework for understanding sustainable tourism management. In B. Bramwell, I. Henry, G., Jackson, A. G. Prat, G. Richards, \& J. Van der Straaten, (Eds.), Sustainable tourism management: Principles and practices (pp. 23-71). Tilburg, NL: Tilburg University Press

[7] Buckley, R. (2009). Evaluating the net effects of ecotourism on the environment: a framework, first assessment and future research. Journal of Sustainable Tourism, 17(6), 643-672

[8] Butler, R. (1992). Alternative Tourism: The Thin Edge of the Wedge. In V. L. Smith, and W. R. Eadington, (Eds.), Tourism Alternatives (pp. 31-46). Philadelphia, PA: University of Pennsylvania Press

[9] Butler, R. (1993). Interview with Richard Butler. Journal of Sustainable Tourism, 1(2), 137-142

[10] Carreiro, H. (2014, March, 8). Sustainable tourism in India. USA Today. Retrieved from http://traveltips.usatoday.com/ sustainable-tourism-india-12448.html

[11] Cater, E. (1994). Ecotourism in the third world - Problems and prospects for sustainability and the environment. In E. Cater \& G. Lowman (Eds.), Ecotourism: A sustainable option? (pp. 69-86). London, U.K.: John Wiley \& Sons Ltd

[12] Cater, E., \& Lowman, G. (Eds.). (1994). Ecotourism: A sustainable option? Chichester, U.K.: John Wiley \& Sons Ltd.

[13] Cheia, G. (2013). Ecotourism: Definition and concepts. Journal of Tourism, (15), 56-60

[14] Chiutsi, S., Mukoroverwa, M., Karigambe, P., \& Mudzengi, B. K. (2011). The theory and practice of ecotourism in Southern Africa. Journal of Hospitality Management and Tourism, 2(2), 14-21

[15] Cohen, E., \& Cohen, S.A. (2012). Current sociological theories and issues in tourism. Annals of Tourism Research, 39(4), 2177-2202

[16] Croall, J. (1995). Preserve or destroy: Tourism and the environment. London, U.K.: Calouste Gulbenkian Foundation

[17] De Kadt, E. (1992). Making the alternative sustainable: Lessons from development for tourism. In V. Smith, \& W. Eadington (Eds.). Tourism alternatives: Potentials and problems in the development of tourism (pp. 47-75). Philadelphia, PA: University of Pennsylvania Press
[18] Demonja, D., \& Gredičak, T. (2014). Exploring the ,cultural tourism-sustainable development' nexus: The case of Croatia. Scientific Annals of the ,Alexandru Ioan Cuza' University of Iasi: Economic Sciences Series, 61(2), 161-179. doi:10.2478/ aicue-2014-0012

[19] Dimitriou, C. K. (2000). Ecotourism: A different approach. Tourism \& Economy, 27(264), 120-124

[20] Freeman, M. (2014, March, 8). Sustainable tourism in New Zealand. USA Today. Retrieved from http://traveltips.usatoday. com/sustainable-tourism-new-zealand-13524.html

[21] Gauthier, D. A. (1993). Sustainable development, tourism and wildlife. In J. G.. Nelson, R. Butler \& G. Wall (Eds.), Tourism and sustainable development: Monitoring, planning, managing (pp. 59-82). Ontario, CA: University of Waterloo

[22] Georgiev, G. (2010). Rural and ecotourism development in scope of Bulgarian tourism. Scientific Annals of the ,Alexandru Ioan Cuza“ University of Iasi: Economic Sciences Series, 325-339

[23] Gilbert, D. C., Penda and Friel (1994). Issues in sustainability and the national parks of Kenya and Cameroon. In C. P. Cooper \& A. Lockwood (Eds.), Progress in Tourism, Recreation, and Hospitality Management (Vol. 16, pp. 30-45). Chichester, UK: John Wiley \& Sons

[24] Godfrey, K. B. (1998). Attitudes towards 'sustainable tourism' in the UK: A view from local government. Tourism Management, (19)3, 213-224

[25] Green, H., Hunter, C., \& Moore, B. (1990). Assessing the environmental impact of tourism development; Use of the Delphi technique. Tourism Management, 11(2), 111-120

[26] Gunn, C. A. (1994). Tourism planning: Basics, Concepts, Cases. (3rd ed.). London, U.K.: Taylor \& Francis Ltd

[27] Harris, R., \& Leiper, N. (1995). Sustainable development and tourism: An overview. In R. Harris \& N. Leiper (Eds.), Sustainable tourism: An Australian perspective (p. xviii). Oxford, U.K.: Butterworth-Heinemann Ltd

[28] Hawkins, C. (1994). Ecotourism: Opportunities for developing countries. In W. Theobald (Ed.), Global tourism: The next decade (pp. 261-273). Oxford, U.K.: Butterworth-Heinemann Ltd

[29] Hunter, C. (1995). Key concepts for tourism and the environment. In C. Hunter \& H. Green (Eds.), Tourism and the environment: A sustainable option? (pp. 52-92). London, U.K.: Routledge

[30] Inskeep, E. (1991). Tourism planning: An integrated and sustainable development approach. New York, NY: Van Nostrand Reinhold

[31] Ioannides, (1995). A flawed implementation of sustainable tourism: The experience of Akamas, Cyprus. Tourism Management, 16(8), 583-592

[32] Järviluoma, J. (1992). Alternative tourism and the evolution of tourist areas. Tourism Management, 13(1), 118-120

[33] Jefferson, A. (1995). Prospects for tourism- a practitioner's view. Tourism Management, 16(2), 101-105

[34] Koščak, M., Colarič-Jakše, L., \& Veljković, B. (2014). The quest for excellence and a socially responsible approach in the planning process for sustainable tourism development: A case study of Slovenia. Tourism, 62(2), 189-200

[35] Krippendorf, J. (1987). The Holidaymakers: Understanding the impact of leisure and travel. London, U.K.: ButterworthHeinemann Ltd 
[36] Lane, B. (1994). Sustainable rural tourism strategies: A tool for development and conservation. Journal of Sustainable Tourism, 2(1), 102-111

[37] Lindberg, K., Enriquez, J., \& Sproule, K. (1996). Ecotourism questioned: Case studies from Belize. Annals of Tourism Research, (23)3, 543-562

[38] Lu, J., \& Nepal, S. K. (2009). Sustainable tourism research: an analysis of papers published in the Journal of Sustainable Tourism. Journal of Sustainable Tourism, 17(1), 5-16

[39] MacKinnon, B. H. (1995). Beauty \& the beasts of ecotourism: Three tiny towns' very different tacks. Business Mexico, 5(4), 44-47

[40] Mc Kercher, B. (1993). Some fundamental truths about tourism: Understanding tourism's social and environmental impacts. Journal of Sustainable Tourism, 1(1), 6-15

[41] Musarò, P. (2015). Responsible tourism as an agent of sustainable and socially-conscious development: reflections from the Italian case. Recerca, 15, 93-107

[42] Orams, M. B. (1995). Towards a more desirable form of ecotourism. Tourism Management, 16(1), 3-8

[43] Pigram, J. J. (1990). Sustainable tourism: Policy considerations. Journal of Tourism Studies, 1(2), 2-9

[44] Pigram, J. J. (1992). Alternative Tourism: Tourism and sustainable resource management. In V. L. Smith, and W. R. Eadington, (Eds.), Tourism Alternatives (pp. 76-87). Philadelphia, PA: University of Pennsylvania Press

[45] Prosser, R. (1994). Societal change and the growth in alternative tourism. In E. Cater, \& G. Lowman, (Eds.), Ecotourism: A sustainable option? (pp. 19-35). Chichester, U.K.: John Wiley \& Sons Ltd

[46] Romeril, M. (1994). Alternative tourism: The real tourism alternative? In C. P. Cooper, \& A. Lockwood (Eds.), Progress in Tourism, Recreation, and Hospitality Management (Vol. 6, pp. 22-29). Chichester, UK: John Wiley \& Sons

[47] Sandu, E. (2014). Comparative study on the management of sustainable touristic development in Brasov and Brussels counties. Revista De Turism - Studii Si Cercetari In Turism, (18), 69-76

[48] Scace, R. C. (1993). An ecotourism perspective. In J. G.. Nelson, R. Butler \& G. Wall (Eds.), Tourism and sustainable development: Monitoring, planning, managing (pp. 59-82). Ontario, CA: University of Waterloo

[49] Shaw, G., \& Williams, A. (1992). Tourism, development and the environment: The eternal triangle In C. P. Cooper, \& A. Lockwood (Eds.), Progress in Tourism, Recreation, and Hospitality Management (Vol. 4, pp. 47-59). Chichester, UK: John Wiley \& Sons
[50] Smith V., \& Eadington, W. (Eds.). (1992). Tourism alternatives: Potentials and problems in the development of tourism. Philadelphia, PA: University of Pennsylvania Press

[51] Thapa, B. (2013). Visitor segments and attitudes toward sustainable tourism in protected areas: A case study in Zambia. Journal of Park and Recreation Administration, 31(2), 50-60

[52] Timothy, D. J. (1998). Cooperative tourism planning in a developing destination. Journal of Sustainable Tourism, 6(1), 52-68

[53] Todd, S. E. \& Williams, P. W. (1996). From white to green: A proposed environmental management system framework for ski areas, Journal of Sustainable Tourism, (4)3, 147-173

[54] Walker, K., \& Moscardo, G. (2014). Encouraging sustainability beyond the tourist experience: ecotourism, interpretation and values. Journal of Sustainable Tourism, 22(8), 1175-1196

[55] Wall, G. (1997) Sustainable tourism - unsustainable development. In S. Wahab and J.J. Pigram (Eds.), Tourism Development and Growth: The Challenge of Sustainability (pp. 33-49). London: Routledge

[56] Weaver, D. B. (1995). Alternative tourism in Montserrat. Tourism Management, 16(8), 593-604

[57] Weiler, B. (1995). Ecotourism association of Australia. In R. Harris \& N. Leiper (Eds.), Sustainable tourism: An Australian perspective (pp. 63-68). Oxford, U.K.: Butterworth-Heinemann Ltd

[58] Wheeller (1991). Tourism's troubled times: Responsible tourism is not the answer. Tourism Management, 12(1), 91-96

[59] Wheeller (1992a). Is progressive tourism appropriate? Tourism Management, 13(1), 104-105

[60] Wheeller (1992b). Alternative tourism - a deceptive ploy. In C. P. Cooper and A. Lockwood (Eds.), Progress in Tourism, Recreation, and Hospitality Management (Vol. 4, pp. 140-145). Chichester, UK: John Wiley \& Sons

[61] Wheeller (1993a). Sustaining the ego. Journal of Sustainable Tourism, 1(2), 121-129

[62] Wheeller (1993b). Willing victims of the ego-trap. In Focus, 9 , 14

[63] Wheeller, B. (1996). U.K. Focus: In whose interest? In Focus, 19, 14-15

[64] Wight, P. (1993). Ecotourism: Ethics or eco-sell? Journal of Travel Research, 31(3), 3-9

[65] Wild, C. (1994). Issues in ecotourism. In C. P. Cooper, \& A. Lockwood (Eds.), Progress in Tourism, Recreation, and Hospitality Management (Vol. 6, pp. 12-21). Chichester, UK: John Wiley \& Sons

[66] Xu, H., Cui, Q., Sofield, T., \& Li, F. S. (2014) Attaining harmony: understanding the relationship between ecotourism and protected areas in China. Journal of Sustainable Tourism, 22(8), $1131-1150$ 